\title{
KELEKATAN ANAK DENGAN IBU BEKERJA DI ERA DIGITAL
}

\author{
Sriyanti Rahmatunnisa \\ ${ }^{1)}$ PG-PAUD, Fakultas Ilmu Pendidikan, Universitas Muhammadiyah Jakarta, \\ Jl. KH. Ahmad Dahlan Cireundeu - Ciputat, Kode Pos 15419 \\ sriyanti_rachmatunnisa@yahoo.com
}

\begin{abstract}
Abstrak
Tujuan dari penelitian ini adalah untuk mengetahui apa ada kelekatan antara anak dengan ibu yang bekerja, siapa yang mengasuh anaknya dan bagaimana cara ibu menjalin kelekatan dengan anak. Metode yang digunakan dalam penelitian adalah kualitatif single case dengan teknik analisis data Miles dan Huberman. Hasil penelitian menunjukkan walaupun ibu bekerja penuh waktu, tapi tetap menjalin kelekatan dengan cara video call, kelekatan anak dengan ibu menjadikan anak memiliki perkembangan yang baik ditinjau dari perkembangan aspek fisikmotorik, kognitif, bahasa, sosial-emosional, dan spiritual. Penelitian ini memberikan rekomendasi kepada orang tua agar dapat menjalin kelekatan dengan anak, dengan menggunakan berbagai cara, sehingga ibu dapat tetap menghadirkan diri di hadapan anak untuk memenuhi kebutuhan psikologis dan sosiologs anak sehingga anak.
\end{abstract}

Kata Kunci: Kelekatan, Anak, Ibu bekerja, Era Digital.

\begin{abstract}
The purpose of this study is to find out whether there is attachment between children and working mothers, who is caring for their children and how mothers are attached to children. The method used in this research is qualitative single case with Miles and Huberman data analysis techniques. The results showed that even though the mother worked full time, but still established attachment by video call, the attachment of the child to the mother made the child have a good development in terms of the development of physical-motoric, cognitive, language, socialemotional, and spiritual aspects. This study provides recommendations for parents to be able to establish attachment to children, using a variety of ways, so that mothers can still present themselves in front of children to meet the psychological and sociological needs of children so that children.
\end{abstract}

Keywords: Attachment, Children, Working Mother, Digital Era 


\section{PENDAHULUAN}

Usia dini merupakan masa penting sekaligus genting dalam rentang kehidupan manusia, karena masa ini sangat menentukan seluruh area perkembangan anak, baik fisik, kognitif, bahasa, sosial- emosional, , dan spiritual..

Jika membahas mengenai anak, tentu saja tidak dapat dilepaskan dari keluarga sebagai unit terkecil dalam masyarakat. Keluarga memiliki tanggung jawab pertama dan utama dalam pertumbuhan dan perkembangan anak, hal ini tertuang dalam Mukadimah Konvensi Hak-hak Anak butir lima yang menyatakan bahwa "Keluarga sebagai kelompok dasar dari masyarakat dan lingkungan alam bagi pertumbuhan dan kesejahteraan dari seluruh anggotanya terutama anak-anak, harus diberi perlindungan dan bantuan yang diperlukan sehingga ia sepenuhnya dapat memikul tanggung jawab dalam masyarakat. Butir enam, bahwa anak, demi pengembangan sepenuhnya, dan keharmonisan dari kepribadiannya, harus tumbuh dalam lingkungan keluarga, dalam iklim kebahagiaan, cinta kasih dan pengertian". (http://www.unicef.org/voy/media/CR C_bahasa_indonesia_version_pdf).

Peran keluarga tidak hanya menyangkut pemenuhan segala kebutuhan yang bersifat biologis, tapi juga pemenuhan kebutuhan psikologis dan sosiologis yang wujud nyatanya berupa pemberian kasih sayang, rasa aman, rasa diterima dan diakui keberadaannya, serta menanamkan nilai-nilai dalam diri anak. Pendidikan yang didapat anak dalam keluarga akan menjadi dasar agar anak tumbuh kembang optimal sesuai dengan potensi yang dimilikinya, sehingga disamping anak sehat secara fisik, juga memiliki kepribadian yang kuat, tangguh, matang, integratif dan tetap berpijak pada nilai-nilai moral dan agama yang akan menjadi dasar untuk pergaulannya dengan masyarakat yang lebih luas.

Seiring dengan perkembangan zaman, peran orang tua dalam keluarga mengalami perubahan, dimana ayah tidak lagi sebagai pencari nafkah utama bagi keluarga dan ibu tidak lagi hanya sebagai ibu rumah tangga yang hanya mengurus anak di rumah, hal ini dikarenakan ibu-ibu pada masa sekarang memiliki peran ganda, yaitu sebagai pekerja di luar rumah. Pergeseran peran ini tentu saja memiliki dampak pada cara mengasuh anak. Peran ibu sebagai pendidik pertama dan utama mulai terabaikan, kelekatan hubungan antara anak dengan ibu ada kecenderungan mulai berkurang, yang disebabkan karena minimnya waktu yang dimiliki ibu. Dengan alasan kesibukan, ibu mempercayakan sepenuhnya pengasuhan dan pendidikan anak kepada pengasuh, sehingga banyak anak yang "lari" dari keluarga untuk mencari jati dirinya, yang pada akhirnya tidak tertutup kemungkinan anak bersentuhan 
dengan hal-hal yang membahayakan masa depan mereka, juga merugikan orang lain

Berdasarkan penelitian yang dilakukan Devi dengan judul "Proses Komunikasi Interpersonal Ibu Yang bekerja Dalam Pembentukan Sikap Konatif Anak" dalam Jurnal EKomunikasi, Universitas Kristen Petra, Surabaya, 2015, yang meneliti tentang seorang ibu bekerja yang memerlukan manajemen waktu yang baik, agar dapat membagi waktu dan menyeimbangkan antara urusan pekerjaan dan keluarga. Hasil penelitian menunjukkan meskipun penyampaian pesan dilakukan secara personal, tetapi penerimaan pesan tersebut dapat diterima berbeda sesuai dengan hal-hal yang mempengaruhi pemikiran dan pandangan lawan bicara.

Dalam penelitian ini, peneliti memfokuskan penelitian pada subyek anak perempuan yang bernama HIK, berusia 3,5 tahun dan ibu yang bernama AM, yang bekerja sebagai guru SMK. Jam kerja ibu dimulai dari jam 6.30 - 15.00. Setiap pagi ibu berangkat jam 6.00 , dan pulang ratarata pada jam 16.00. Jika dihitung waktu yang dihabiskan oleh ibu sejak berangkat dari rumah sampai kembali ke rumah memakan waktu kurang lebih 10 jam, yang berarti saat ibu tidak berada di rumah, pengasuhan anak sepenuhnya dipercayakan pada orang lain yaitu pengasuh anak, bernama LS dan DD, yang berusia 18 tahun. AM memberikan gawai pada pengasuh dengan maksud untuk tetap dapat berkomunikasi dengan HIK selama bekerja. Setiap hari, rata-rata AM menelepon HIK sebanyak dua atau tiga kali dengan cara video call. Hal ini dimaksudkan agar AM dapat berkomunikasi secara langsung dan melihat apa yang dilakukan oleh HIK selama dirinya bekerja.

Bertolak dari latar masalah yang diuraikan diatas, maka dapat dirumuskan permasalahan dalam penelitian ini adalah: bagaimana cara ibu bekerja menjalin kelekatan dengan anak.

Tujuan penelitian ini adalah untuk mengetahui kelekatan ibu bekerja dengan anak yang diasuh oleh orang lain.

Manfaat penelitian ini untuk membuka wawasan bagi orang tua bahwa kelekatan merupakan kebutuhan psikologis yang sangat mendasar bagi anak, karena bagaimana anak diasuh dan seperti apa kualitas hubungan anak dengan orang tua akan memberi dampak pada pembentukan kepribadian anak.

\section{Hakikat Kelekatan (Attachment) Pengertian Kelekatan (Attachment)}

Dalam proses tumbuh kembang anak, orang tua memegang peran yang sangat penting. Bagaimana anak diasuh dan seperti apa kualitas hubungan anak dengan orang tua akan sangat berpengaruh pada pembentukan kepribadian anak. Hal 
penting yang harus menjadi perhatian orang tua adalah terpenuhinya kebutuhan-kebutuhan anak. Pemenuhan kebutuhan-kebutuhan tersebut dapat diupayakan dengan membina kelekatan (attachment) antara anak dengan orang tua.

Menurut Feldman, Papalia, Old (2009: 278), Kelekatan (attachment) adalah ikatan emosional menetap yang bertimbal balik antara anak dan orang tua, yang masing-masing berkontribusi terhadap kualitas hubungan tersebut. Kelekatan (attachment) memiliki nilai adaptif bagi anak, memastikan bahwa kebutuhan psikososial dan fisik anak akan dipenuhi. Selanjutnya Baron (2009:5), menyatakan bahwa kelekatan (attachment) adalah ikatan interpersonal antara anak dan orang tua yang diwarnai dengan kasih sayang

Pendapat lain mengenai kelekatan (attachment) dikemukakan oleh Berk (2007:5) yang menyatakan bahwa kelekatan (attachment) adalah ikatan kuat kasih sayang antara anak dengan orang tua atau orang-orang yang khusus dalam hidup anak, yang menuntun anak untuk merasakan kesenangan ketika anak berinteraksi dengan mereka. Selanjutnya Santrock (2002:196), berpendapat bahwa kelekatan (attachment) mengacu kepada suatu relasi antara dua orang yang memiliki perasaan kuat satu sama lain dan melakukan banyak hal bersama untuk melanjutkan relasi itu.
Menguatkan pendapat sebelumnya, Atmodiwiryo (2008:9), menyatakan bahwa kelekatan (attachment) adalah interaksi orang tua dengan anak secara langsung yang diwarnai dengan perilaku cinta kasih dan keterlibatan dalam kegiatan bersama yang akan memungkinkan terjadinya stimulasi kognitif, emosional dan sosial.

Berdasarkan pendapat para ahli di atas, dapat disimpulkan bahwa kelekatan (attachment) adalah ikatan emosional antara anak dan orang tua, ada interaksi positif antara anak dengan orang tua, dan terpenuhi kebutuhan fisik dan psikososial anak, dengan indikator anak dapat secara terbuka mengungkapkan pikiran dan perasaannya pada orang tua, anak dapat berinteraksi dan berkomunikasi secara baik dengan orang tua, dan anak dapat merasakan perhatian, kasih sayang, dan rasa aman.

\section{Periode Kelekatan (Attachment) Anak Dengan Orang Tua}

Periode pranatal merupakan periode perkembangan pertama dalam rentang kehidupan manusia. Aspek terpenting pada periode ini adalah ibu harus siap secara fisik dan mental, bersikap dewasa, dan memelihara kehamilan secara baik. Hal ini penting, karena kondisi positif dan negatif pada ibu akan berpengaruh secara langsung pada janin yang dikandungnya.

Setelah bayi lahir, kelekatan tetap sangat dibutuhkan, agar bayi merasa 
diterima, merasa aman dan nyaman. Kelekatan pertama dan utama setelah bayi lahir adalah dengan inisiasi dini, yaitu permulaan kegiatan menyusui dalam satu jam pertama setelah bayi lahir. Selanjutnya kelekatan tetap dijalin dengan pemberian ASI eksklusif. Untuk itu pemerintah memberlakukan pelarangan penayangan iklan susu formula di televisi terhitung sejak tahun 2011, hal ini dimaksudkan agar bayi disamping mendapatkan haknya atas ASI sebagai makanan pertama dan utama, juga agar terjalin kelekatan yang aman antara ibu dengan bayi.

Berdasarkan teori Psikoseksual Freud, dalam Papalia, Old, Feldman (2009: 46), manusia berkembang melewati beberapa fase psikoseksual, salah satu fasenya adalah fase oral. Pada fase ini sumber kenikmatan bayi mencakup berbagai aktivitas yang berorientasi pada mulut. Pengalaman anak dipusatkan pada pengalaman oral yang juga sebagai sumber kenikmatan. Secara natural bayi mendapatkan kenikmatan tersebut dari ibu disaat bayi menghisap susu dari payudara ibu atau bayi mendapatkan stimulasi oral dari ibu. Proses ini menjadi penyimpanan energi libido bayi, dan ibu selanjutnya menjadi objek cinta pertama seorang bayi.

Mengenai kelekatan antara bayi dengan ibunya, Berk (2007: 149), mengungkapkan ketika ibu menghampirinya, biasanya bayi akan tersenyum bahagia, lalu ketika ibu menggendong dan menepuk wajahnya serta membelai rambutnya secara otomatis bayi akan merapatkan tubuhnya ke tubuh ibunya, demikian pula ketika bayi merasa cemas, ia akan merangkak kepangkuan ibunya dan menempel erat.

Bowlby dalam Berk (2007:420), menggambarkan bahwa hubungan bayi dengan orang tua, dimulai dengan satu set sinyal, dimana bayi merasakan keberadaan orang dewasa, dalam hal ini ibu yang berada dekat disampingnya. Seiring waktu ikatan kasih sayang berkembang melalui perawatan, kehangatan dan kepekaan ibu dalam merespon suara dan bahasa tubuh bayi. Masih menurut Bowlby (2007:421), kelekatan berkembang dalam empat tahap, pertama Preattachment phase ( lahir - 6 minggu), sinyal seperti menggenggam, tersenyum, menangis, dan menatap ke mata orang dewasa membantu membawa bayi yang baru lahir ke dalam kontak dekat dengan manusia lain. Ketika orang dewasa dalam hal ini ibu sering berada di dekatnya dan merespon suara dan gerakan bayi, maka bayi merasa aman dan nyaman. Selanjutnya bayi akan mengenali bau, suara, dan segera mengenali wajah ibunya. Ke dua Attachment-in-the making phase (6 minggu sampai 6-8 bulan), selama fase ini respon bayi terlihat berbeda terhadap pengasuh yang sering berada didekatnya dalam hal ini ibunya dengan orang asing. Bayi akan tersenyum, tertawa, dan berceloteh lebih bebas dengan ibu, 
dan pada fase ini bayi belajar bahwa tindakan mereka mempengaruhi perilaku orang-orang di sekitar mereka. Bayi juga mulai mengembangkan rasa kepercayaan dan harapan bahwa pengasuh akan merespon sinyal-sinyal yang mereka tampilkan. Ke tiga, "clear-cut" attachment phase ( 6-8 bulan sampai 18 bulan-2 tahun), pada fase ini kelekatan antara anak dengan ibu semakin jelas. Bayi akan menampilan kecemasan (separation-anxiety), jika ibu tidak segera datang saat bayi membutuhkan. Ke empat formation of a reciprocal relationship (2 tahun sampai seterusnya), pada akhir tahun kedua anak sudah memahami beberapa faktor yang mempengaruhi ibu datang dan pergi, dan dapat memprediksi kapan ibu kembali. Pada fase ini perpisahan dengan ibu memunculkan protes.

Menurut Papalia, Old, Feldman (2009: 46), model kerja tentang kelekatan berhubungan dengan konsep basic truts Erikson. Kelekatan aman mencerminkan rasa percaya, kelekatan tak aman mencerminkan rasa tidak percaya. Anak dengan kelekatan aman belajar untuk menaruh rasa percaya bukan saja pada orang tuanya, tetapi juga pada kemampuan mereka sendiri dalam mendapatkan yang mereka butuhkan. Ainsworth berpendapat, para ibu dari bayi dan anak dengan kelekatan aman cenderung bersifat sensitif dan responsif
Menurut Braungart dalam Papalia, Old, Feldman (2009: 280), interaksi timbal balik, stimulasi, sikap positif, kehangatan dan penerimaan serta dukungan emosional merupakan hal penting dari kelekatan.

Berdasarkan pendapat para ahli dapat disimpulkan bahwa periode kelekatan adalah fase-fase kelekatan yang terjalin antara anak dengan orang tua. Kelekatan akan sangat mempengaruhi kondisi jasmaniah, bentuk temperamen dan kehidupan psikis anak serta cenderung membuat anak bersifat sensitif dan responsif.

\section{Pengaruh Kelekatan Terhadap Kompetensi Emosional, Sosial dan kognitif.}

Menurut teori kelekatan yang dikemukakan Van Ijzendoorn dan Sagi, dalam Papalia, Old, Feldman (2009: 284), rasa aman dari kelekatan sepertinya mempengaruhi kompetensi emosional, sosial, dan kognitif. Makin aman kelekatan seorang anak terhadap orang dewasa yang bersifat mengasuh, tampak makin mudah bagi anak untuk mengembangkan hubungan yang baik dengan orang lain. Arend, Gove, dan sroufe dalam Papalia, Old, dan Feldman (2009: 285), mengatakan, anak dengan kelekatan aman tumbuh lebih ingin tahu, kompeten, empati, ulet, dan percaya diri, lebih akur dengan anak lain, dan menjalin persahabatan yang erat dari pada anak dengan kelekatan tak aman. Kelekatan (attachment), membuat 
anak berinteraksi lebih positif dengan orang tua, guru, dan teman sebaya, serta lebih mampu menyelesaikan konflik Pendapat Meins dalam Papalia Old, dan Feldman (2009:286), mengaitkan kelekatan dengan kemampuan berbahasa pada anak, anak dengan kelekatan yang aman cenderung memiliki kosakata yang lebih banyak daripada anak yang kelekatannya tidak aman Hasil studi Papini, Roggman dan Anderson dalam Santrock (2002: 41) Attachment (kelekatan) yang kokoh dengan orang tua meningkatkan relasi teman sebaya yang kompeten dan relasi erat yang positif di luar keluarga.

\section{Ibu Bekerja}

Menurut Rimm (2010 : 228) ketika seorang ibu mengambil keputusan untuk bekerja, maka tanggung jawab pengasuhan diserahkan kepada orang lain, biasanya kepada keluarga dekat.

Menurut Hurlock (1999:199), ibu bekerja adalah ibu yang bekerja di luar rumah dan menyerahkan tugas rumah tangga dan pengasuhan anak kepada pengasuh. Menurut Gerungan (2010 : 228), jumlah kaum wanita yang bekerja di luar rumah semakin banyak, dengan alasan ekonomi atau aktualisasi diri, sehingga urusan rumah tangga dan pengasuhan anak diserahkan kepada keluarga dekat

Berdasarkan pendapat para ahli, dapat disimpulkan bahwa ibu bekerja adalah ibu yang memutuskan untuk bekerja di luar rumah, dimana tanggung jawab untuk merawat dan mengasuh anak diserahkan kepada orang lain, baik keluarga dekat maupun yang tidak memiliki ikatan keluarga yang akan menggantikan peran dan tugas ibu selama bekerja di luar rumah

\section{Era Digital}

Menurut Irsyam dalam artikel revolusi digital, Koran Suara Merdeka (11 November 2013), era digital merupakan era dimana aliran informasi melalui media-media komunikasi bersifat jelas, akurat dan cepat. https://id.m.wikipedia.org, teknologi komunikasi digital adalah teknologi komunikasi jarak jauh. Teknologi ini memungkinkan seseorang dapat mengirim atau menerima informasi ke atau dari pihak lain yang letaknya berjauhan Teknologi ini membuat jarak seperti tidak ada. Komunikasi dapat dijalin secara online. Menurut Terras dan Ramsay dalam Jurnal Frontier in Psychology volume 7 tahun 2016, anak-anak walaupun yang paling kecil sekalipun, mereka memiliki pengalaman yang kaya tentang teknologi. Penelitian yang dilakukan di UK terhadap 346 orang tua yang memiliki anak usia 3 - 5 tahun mengindikasikan jika anak mereka memiliki pengalaman teknologi di rumah seperti bermain games di handphone atau computer.

Berdasarkan pendapat di atas dapat disimpulkan bahwa era digital adalah era dimana aliran informasi melalui media-media komunikasi 
bersifat jelas, akurat dan cepat, teknologi ini memungkinkan seseorang dapat mengirim atau menerima informasi ke atau dari pihak lain yang letaknya berjauhan, sehingga membuat jarak seperti tidak ada. Komunikasi dapat dijalin secara online.

\section{METODE PENELITIAN}

\section{Tempat dan Waktu Penelitian}

Penelitian dilakukan di kediaman keluarga UK, yang berlokasi di Jl. Bangunan Barat, Kelurahan Kayu Putih, Jakarta Timur. Penelitian ini menggunakan metode kualitatif, Menurut Sugiyono (2009: 8), metode penelitian kualitatif sering disebut metode penelitian naturalistik karena penelitiannya dilakukan pada kondisi yang alamiah (natural setting). Kehadiran peneliti tidak mempengaruhi dinamika pada objek tersebut. Instrumen utama dalam penelitian ini adalah peneliti sendiri (human instrument) atau the key instrument (instrumen kunci). Teknik pengumpulan data dilakukan secara triangulasi. Menurut Sugiyono (2009: 293), dalam penelitian kualitatif, teknik pengumpulan data yang utama adalah observasi, wawancara, studi dokumentasi. Analisis data kualitatif menurut Miles dan Huberman dalam Sugiyono (2009: 294), dilakukan secara interaktif melalui proses data reduction, data display, dan verification. Analisis data merupakan proses berkelanjutan yang membutuhkan refleksi terus menerus terhadap data, mengajukan pertanyaan analisis, dan menulis catatan singkat sepanjang penelitian. Analisis data melibatkan pengumpulan data yang terbuka, yang didasarkaan pada pertanyaan umum, dan analisis informasi dari partisipan.

\section{Pemerikasaan Keabsahan Data}

Menurut Sugiyono (2009: 2960), uji kredibilas data atau uji keabsahan data dilakukan dengan: perpanjangan pengamatan, meningkatkan ketekunan, dan triangulasi.

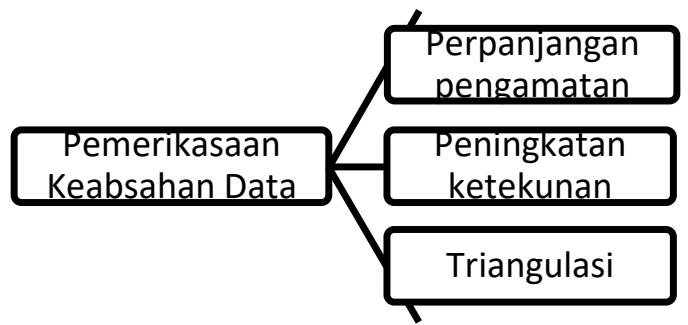

Pemeriksaan Keabsahan Data

\section{HASIL DAN PEMBAHASAN Proses Terbentuknya Kelekatan HIK dan AM}

Sebagai ibu yang juga bekerja AM menyatakan bahwa keluarga tetap menjadi prioritas utama. Sebelum berangkat kerja AM membangunkan HIK terlebih dahulu agar dapat berpamitan, selanjutnya pengasuhan dan perawatan total dilakukan pengasuh. Menurut AM untuk menutupi ketidak hadiran AM secara fisik saat bekerja, AM memanfatkan gawai untuk tetap dapat berkomunikasi dengan HIK agar HIK tetap merasakan kehadiran AM walaupun hanya melalui video call, Karena usianya yang baru 3,5 tahun gawai dipegang oleh pengasuh.. Pada 
jam 7.00 ibu melakukan video call untuk ngobrol sejenak dengan HKI menanyakan apakah sudah mandi, dan melihat HKI sarapan. Jika HIK sudah mandi AM memberikan pujian. Jam 12.00 AM kembali video call, pembicaraan pada siang hari waktunya lebih panjang, karena ibu sedang istirahat, jadi lebih leluasa untuk ngobrol dengan HKI, ibu memantau langsung saat makan siang dan HIK bisa bercerita apa saja kejadian yang dialami sejak pagi. Jam 3 sesaat sebelum ibu menyelesaikan pekerjaan dan pulang, ibu kembali video call, kadang HKI sedang bermain, kadang sedang tidur siang. Sesuai dengan teori Feldman, Papalia, Old (2009: 278), Kelekatan (attachment) memiliki nilai adaptif bagi anak, memastikan bahwa kebutuhan psikososial dan fisik anak akan dipenuhi. Baron (2009:5), menyatakan bahwa kelekatan (attachment) adalah ikatan interpersonal antara anak dan orang tua yang diwarnai dengan kasih sayang, Berk (2007:5 kelekatan (attachment) adalah ikatan kuat kasih sayang antara anak dengan orang tua atau orang-orang yang khusus dalam hidup anak, yang menuntun anak untuk merasakan kesenangan ketika anak berinteraksi dengan mereka. Saat AM dan HKI berbincang melalui video call, terlihat HIK sangat senang, saat sedang menangispun bisa langsung diam dan tersenyum, jika HIK ingin menceritakan kejadian yang dialaminya biasanya HIK berkata "mamah HK cerita deh" lalu HIK menceritakan apa saja yang terjadi, atau HIK memperlihatkan hasil coretan di kertas yang HIK sebut sebagai gambar, memperlihatkan susunan lego yang dibuatnya dan lain sebagainya. Saat pulang kerja AM selalu memberi kesempatan pada pengasuh untuk istirahat, selanjutnya total perawatan dan pengasuhan HIK diambil alih, pengasuh hanya membantu jika diperlukan, membersihkan saat HIK pipis, membuat susu, menemani saat makan buah/pudding, bermain atau bercerita total dilakukan bersama antara AM dengan HIK. Saat ayahnya pulang kerja sekitar jam 17.00, ayahnya juga terlibat untuk bermain dengan HIK.

\section{Pengaruh Kelekatan Terhadap Kompetensi Emosional, Sosial dan kognitif.}

Sesuai teori yang dikemukakan Atmodiwiryo (2008:9), bahwa kelekatan (attachment) adalah interaksi orang tua dengan anak secara langsung yang diwarnai dengan perilaku cinta kasih dan keterlibatan dalam kegiatan bersama yang akan memungkinkan terjadinya stimulasi kognitif, emosional dan sosial. Menurut teori kelekatan yang dikemukakan Van Ijzendoorn dan Sagi, dalam Papalia, Old, Feldman (2009: 284), rasa aman dari kelekatan sepertinya mempengaruhi kompetensi emosional, sosial, dan kognitif. Makin aman kelekatan seorang anak terhadap orang dewasa 
yang bersifat mengasuh, tampak makin mudah bagi anak untuk mengembangkan hubungan yang baik dengan orang lain. Arend, Gove, dan sroufe dalam Papalia, Old, dan Feldman (2009: 285), mengatakan, anak dengan kelekatan aman tumbuh lebih ingin tahu, kompeten, empati, ulet, dan percaya diri, lebih akur dengan anak lain, dan menjalin persahabatan yang erat dari pada anak dengan kelekatan tak aman. Kelekatan (attachment), membuat anak berinteraksi lebih positif dengan orang tua, guru, dan teman sebaya, serta lebih mampu menyelesaikan konflik Pendapat Meins dalam Papalia Old, dan Feldman (2009:286), mengaitkan kelekatan dengan kemampuan berbahasa pada anak, anak dengan kelekatan yang aman cenderung memiliki kosakata yang lebih banyak daripada anak yang kelekatannya tidak aman Hasil studi Papini, Roggman dan Anderson dalam Santrock (2002: 41) Attachment (kelekatan) yang kokoh dengan orang tua meningkatkan relasi teman sebaya yang kompeten dan relasi erat yang positif di luar keluarga. Kelekatan HKI dengan AM berdampak pada kompetensi kognitif yaitu HKI lebih cepat menghafal doadoa harian, surat-surat pendek atau hafal lagu-lagu yang diajarkan AM dan diajarkan di tempat mengaji dibandingkan anak seusianya, rasa ingin tahunya tinggi, terlihat dari HIK yang banyak bertanya tentang segala sesuatu yang ingin diketahuinya. Jika bermain lebih suka memanipulasi alat-alat bermainnya, misalnya membentuk dengan play dough, mengkonstruksi lego atau balok menjadi bangunan sesuai imajinasinya, menyusun kursi, membuat rumah-rumahan dan berbagi kapling dengan temannya dengan dihalangi kontainer plastik tempat mainannya. Dalam hal kemampuan berbahasa HKI memiliki kosakata yang cukup banyak dan sudah mampu menyusun kalimat yang dapat dipahami, terlihat ketika dia bercerita,baik bersama ibu dan ayahnya atau dengan orang lain, HIK sudah mampu menggunakan huruf " $\mathrm{r}$ " dengan jelas (tidak cadel), mampu mengungkapkan keinginan secara jelas, jika menceritakan sesuatu alurnya jelas, dan bisa berargumentasi, sebagai contoh jika HIK disuruh mengerjakan sesuatu dan tidak ingin melakukannya dia akan berkata "mamah aku tuh cape" menurut AM kata tersebut suka diungkapkan AM saat sedang kelelahan. Secara emosional HKI dapat meregulasi emosinya terlihat ketika bermain bersama dengan teman sebayanya, HIK dapat mengikuti aturan main yang disepakati bersama dengan temantemannya, lebih ulet. membereskan kembali mainan yang digunakannya dengan bantuan. Kemampuan sosial HKI berkembang dengan baik yaitu dapat bergaul dengan teman sebaya atau pun menjalin komunikasi dengan orang dewasa. jika minta bantuan 
pengasuh atau siapapun pasti menggunakan kata "tolong", jika menerima sesuatu pasti mengucapkan "terima kasih" selalu salam jika bertemu dengan anggota keluarga atau teman ibu dan ayahnya yang datang atau dikunjungi, HKI memiiki rasa percaya diri yang tinggi terlihat saat mengungkapkan apa yang ada dalam pikirannya maupun menurut perasaannya, akan disampaikan secara runtun.

\section{SIMPULAN DAN SARAN}

Simpulan

Di era digital, ibu yang bekerja penuh waktu tetap dapat berkomunikasi dan berinteraksi dengan anak di rumah dengan memanfaatkan video call, sehingga ibu bekerja dapat tetap menjalin kelekatan dengan anak sebagai alternatif untuk menutupi ketidak hadiran ibu secara fisik, agar anak tetap dapat merasakan kehadiran ibu. Kelekatan anak dengan ibu menjadi penting, karena kelekatan memiliki nilai adaptif bagi anak untuk memastikan bahwa kebutuhan psikososial dan fisik anak akan dipenuhi. Dengan pemanfaatan video call ibu tetap dapat melakukan stimulasi kognitif, bahasa, emosional dan sosial.

Hasil penelitian membuktikan bahwa kelekatan yang terjalin walau melalui video berdampak pada kompetensi kognitif, HKI Di usianya yang baru 3,5 tahun HKI telah mampu menghafal doa-doa harian, surat-surat pendek, melantunkan

Asmaul husna atau hafal lagu-lagu yang diajarkan AM, dan diajarkan di tempat mengaji dibandingkan anak seusianya, mengenal warna dan beberapa huruf, rasa ingin tahunya tinggi, terlihat dari HIK yang banyak bertanya tentang segala sesuatu yang ingin diketahuinya, suka memanipulasi alat-alat bermainnya menjadi bentuk-bentuk sesuai imajinasinya. Dalam hal kemampuan berbahasa, HKI memiliki kosakata yang cukup banyak dan sudah mampu menyusun kalimat yang dapat dipahami. HIK sudah mampu menggunakan huruf " $r$ " dengan jelas (tidak cadel), mampu mengungkapkan keinginan secara jelas, jika menceritakan sesuatu alurnya jelas, dan bisa berargumentasi. Secara emosional HKI dapat meregulasi emosinya terlihat ketika bermain bersama dengan teman sebayanya, HIK dapat mengikuti aturan main yang disepakati bersama dengan temantemannya, lebih ulet. membereskan kembali mainan yang digunakannya. Kemampuan sosial HKI berkembang dengan baik dapat bergaul dengan teman sebaya atau pun menjalin komunikasi dengan orang dewasa. HKI juga terbiasa menggunakan kata “tolong", "permisi”, "maaf", "terimakasih", tidak canggung saat berkomunikasi dengan orang dewasa.

\section{Saran}


Hasil penelitian ini dapat nilai-nilai dalam diri anak, sehingga mengingatkan orang tua bahwa anak merasa dihargai, merasa penting, kesibukan tidak boleh menjadi merasa dicintai. Melalui kelekatan ibu penghalang untuk menjalin kelekatan juga dapat smemberikan stimulasi yang aman dengan anak. karena kognitif, emosional dan sosial.

kebutuhan anak tidak terbatas hanya Kelekatan dapat dijalin pada pemenuhan kebutuhan biologis dengan berbagai cara, alternatif yang saja, ada kebutuhan psikologis dan dapat dipilih oleh ibu bekerja adalah sosiologis yang juga harus dipenuhi, dengan pemanfaatan video call. Saat yang wujud nyatanya berupa ibu bekerja pulang ke rumah pemberian kasih sayang, rasa aman, manfaatkan waktu untuk menjalin rasa diterima dan diakui kelekatan dengan cara mengambil keberadaannya, serta menanamkan alih kembali tugas pengasuh. 


\section{DAFTAR PUSTAKA}

Atmowiryo, Ediastri Toto. 2004. Optimalisasi Perkembangan Anak. Jakarta: Fakultas Psikologi Universitas Indonesia.

Berk, Laura E. 2007. Child Development, Seventh Edition. Illinois State University: Pearson.

Baron, Robert A, Donn Byrne. Psikologi Sosial. Edisi kesepuluh Jilid 2. Jakarta: Erlangga.

Devi Lisa. 2015. Proses Komunikasi Interpersonal Ibu Yang bekerja Dalam Pembentukan Sikap Konatif Anak. Jurnal E-Komunikasi Universitas Kristen Petra Surabaya. Volume 3 No. 1.

Feldman, Papalia Olds. 2009. Human development, Perkembangan Manusia. Buku 1. Alih Bahasa Brian Marswendy. Jakarta: Salemba Humanika. Gerungan, W.A. 2010. Psikologi Sosial. Jakarta: PT Eresco
Hurlock, B Elizabeth. 1999.

Perkembangan Anak. Jakarta: Erlangga

Irsyam, Muhammad. 11 November 2013. Revolusi Digital. Koran suara merdeka.

Rimm, Sylvia. 2003. Mendidik dan menerapkan Disiplin Pada anak Prasekolah. Jakarta: Gramedia.

Santrock, John W. 2002. Life Span Development, Suatu Pendekatan Sepanjang Rentang Kehidupan. Jakarta: Erlangga.

Sugiyono. 2009. Metode Penelitian Kuantif, Kualitatif, dan R\&D. Bandung: Alfabeta

Terras, M Melody and Ramsay Judith. 2016. Family Digital Literaccy Practices and Children's Mobile Phone Use. Frontiers in Psychology Volume 7 December.

http://www.unicef.org/voy/media/CR C_bahasa_indonesia_version _pdf.

https://id.m.wikipedia.org. 